\title{
Acute fulminating amoebic colitis: survival after total colectomy
}

\author{
R R BABB AND M L TROLLOPE \\ From the Departments of Medicine and Surgery, Palo Alto Medical Clinic, Palo Alto, California, USA
}

SUMmARY Acute fulminating amoebic colitis is a very uncommon complication of amoebiasis. Most patients die, with or without surgery. We report such a patient who survived after total colectomy. If an excision of diseased colon is done, an exteriorising procedure should be added and primary anastomosis avoided.

Most humans harbouring the protozoan parasite Entamoeba histolytica feel well. ${ }^{1}$ If symptoms occur, and the infection is promptly recognised, appropriate antiamoebic therapy is usually curative. Occasionally, however, a virulent host response to the amoebic infection occurs leading to an acute fulminating colitis, with possible perforation, peritonitis, and death. ${ }^{2}$

We recently cared for a critically ill patient with acute fulminating amoebic colitis who survived after a total colectomy. This case serves as a reminder that amoebic colitis may present with signs of an acute abdomen. The role of surgery in this situation will also be discussed.

\section{Case history}

A 55 year old woman came to the Palo Alto Medical Clinic after several days of lower abdominal cramping and haematochezia. Except for severe chronic constipation necessitating a subtotal colectomy in 1978, her general health had been excellent. She frequently visited Mexico, the last trip being two months before the above symptoms appeared. Her physical examination, including sigmoidoscopy to $20 \mathrm{~cm}$, was normal. There was no stool or exudate in the rectum to smear for ova and parasites. She was advised to return for further evaluation, but failed to do so.

One week later, she was admitted to the hospital because of increasing lower abdominal pain. She

Address for correspondence: Richard R Babb, MD, Palo Alto Medical Clinic, 300 Homer Avenue, Palo Alto, CA, 94301, USA.

Received for publication 18 May 1984 denied fever, chills, diarrhoea or further rectal bleeding. Except for slight abdominal tenderness, her physical examination was normal. She refused the usual bowel preparation, and a barium enema the next morning was felt to be uninterpretable. Her abdominal discomfort left, and she demanded to be discharged from the hospital.

Two days later the patient was brought to the emergency room by her family after being found at home, virtually unresponsive, complaining of abdominal pain. On examination she was hypothermic, in shock, and tender throughout the abdomen. Except for a raised white cell count, her initial complete blood count, liver and kidney function tests were normal. A plain film of the abdomen showed scattered areas of gas throughout the bowel.

The patient was felt to have both sepsis and an acute abdomen, although the underlying cause was not clear. Soon after admission, an exploratory laporotomy was done. The colon was found to be infarcted from the caecum to the peritoneal reflection. A total abdominal colectomy was performed with establishment of an ileostomy and low Hartmann's pouch.

Despite multiple antibiotic drug therapy, the patient continued to show signs of sepsis. Thus, on the fifth postoperative day, the rectum was removed via an abdominal perineal resection.

That same day the pathology report from the first operation was obtained and showed severe transmural necrosis of the colon, mucosal ulcerations, and trophozoites of Entamoeba histolytica scattered throughout the bowel wall (Figure). 


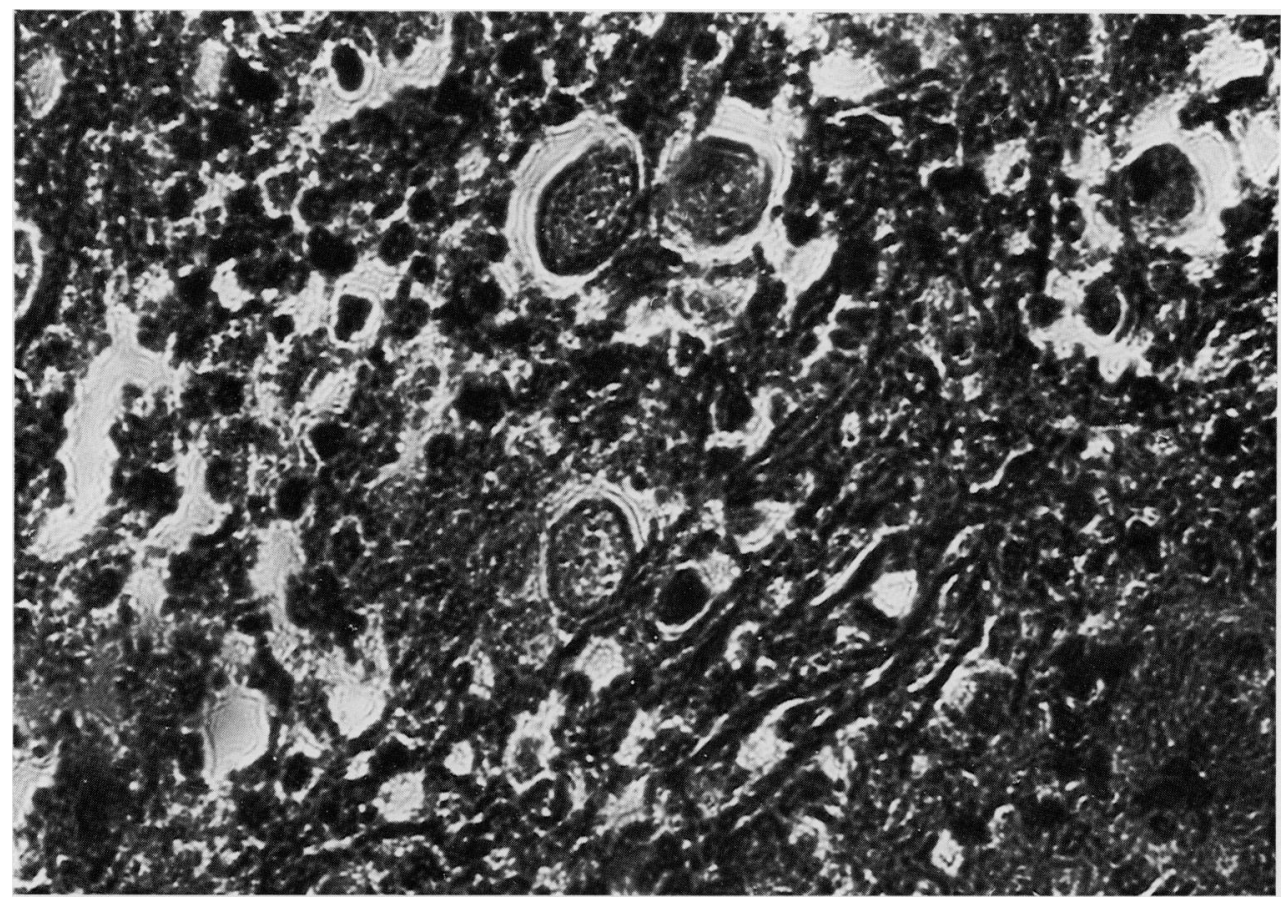

Figure Trophozoites of E. histolytica in the necrotised colon wall (hematoxylin-eosin, original magnification $\times 1000$ ).

Subsequently, the rectal specimen revealed the same findings - that is, transmural necrosis and trophozoites of Entamoeba histolytica scattered throughout.

Metronidazole $750 \mathrm{mg}$ every six hours was started immediately and continued for 14 days. A computed tomography scan of the liver with contrast showed numerous irregular areas in both lobes. Ten days later the scan was much improved. The patient's postoperative course was difficult and complicated by toxic psychosis, adult respiratory distress syndrome, pneumonia, and recurrent urinary tract infections. Nonetheless, she left the hospital after a six week stay afebrile, without abdominal pain, and with a normal functioning ileostomy. Six months later she remains well and has recently left for another trip to Mexico.

\section{Comment}

Because of continuing unsanitary conditions in both urban and rural areas, ${ }^{14}$ increasing worldwide travel, ${ }^{5}$ a large reservoir of infection in the homosexual community, ${ }^{6}$ and even unsterile medical equipment, ${ }^{7}$ amoebic dysentery and its complications continues to be a health problem in the United States. It has been estimated that up to
$5 \%$ of Americans, ${ }^{8} 2 \%$ of travellers, ${ }^{5}$ and $20 \%$ of homosexual males ${ }^{6}$ are infected with $E$ histolytica.

The exact cause of tissue invasion by the often harmless $E$ histolytica trophozoite is not clear, but release of enzymes or toxins by the parasite and immunologic mechanisms have been implicated. ${ }^{12}$ Pathology of the invaded colonic tissue shows a spectrum of changes ranging from minute, discrete, mucosal ulcerations to transmural inflammation, and even widespread necrosis. ${ }^{39}$

The diagnosis of amoebic colitis may be exceedingly difficult, and rests on finding the characteristic trophozoites in stool or biopsy specimens. Stools and exudate obtained at the time of sigmoidoscopy should be examined both in the fresh state and after preparation of permanently stained smears. Serologic tests, colon biopsies, and barium enema examination may also be helpful. ${ }^{1} 2410$

The vast majority of patients with amoebic dysentery are cured with appropriate antiamoebic drug therapy. ${ }^{2}$ Fulminating colitis is very uncommon occurring in only $3 \%$ of 3013 patients reported from South Africa. ${ }^{2}$ Between one and four such cases are seen per year in large hospitals of India, ${ }^{11} 12$ Thailand, ${ }^{13}$ and Mexico. ${ }^{14}$ If fulminating colitis and peritonitis develops, the mortality rate is high 
ranging from $50-100 \%$ in several published series. ${ }^{19-15}$ Adams and MacLeod ${ }^{2}$ found the case fatality rate rose from $0.5 \%$ in uncomplicated cases of amoebic dysentery to $40 \%$ once peritonitis developed. In a study of 148 cases of fatal amoebiasis, Kean et al $^{16}$ noted the commonest cause of death to be peritonitis.

Several authors ${ }^{17-20}$ have listed various indications for surgical intervention in amoebic colitis, and these have been summarised in the Table. In our case, as in many others, surgery was undertaken because of a worsening clinical condition in a patient with an acute abdomen. The diagnosis of necrotising amoebic colitis was made postoperatively after pathologic analysis of the resected colon. Even when the diagnosis of amoebic colitis is made and drug therapy started, however, some patients deteriorate and require surgery for survival. ${ }^{12} 1.320$

The type of surgical procedure required in fulminating amoebic colitis will depend on the extent of colonic injury found at surgery. Because there is a high risk of suture breakdown in tissue containing amoebae, resection and anastomosis should be avoided. ${ }^{17}{ }^{21}$ In a necropsy study of fatal amoebic colitis, Azar $e a^{3} l^{3}$ found gangrenous areas of colon both proximal and distal to anastomotic sites, and noted anastomotic leaks in two others. Experienced surgeons ${ }^{13}{ }^{17} 21$ recommend diverting and exteriorising procedures if an excision is carried out. It is hoped that drug therapy will heal any residual colitis postoperatively, and intestinal continuity can be restored at a future date.

Table Possible indications for surgery in amoebic colitis $^{17-20}$

\begin{tabular}{ll}
\hline 1 & Free perforation of bowel with peritonitis \\
2 & Perforation of bowel with localised abscess. \\
3 & Perforation of hepatic abscess into peritoneal cavity. \\
4 & $\begin{array}{l}\text { Fulminating colitis with worsening of paticnt's } \\
\text { condition, with or without antiamoebic therapy. }\end{array}$ \\
5 & $\begin{array}{l}\text { Bowel obstruction secondary to amoeboma. } \\
6\end{array}$ \\
7 & $\begin{array}{l}\text { Ileocecal intussusception secondary to amoeboma. } \\
\text { Severe symptoms secondary to postamoebic colitis not } \\
\text { responsive to medical therapy. }\end{array}$ \\
\hline
\end{tabular}

\section{References}

1 Patterson M, Schoppe L. The presentation of amoebiasis. Med Clin North Am 1982; 66: 689-705.

2 Adams EB, MacLeod IN. Invasive amebiasis. Medicine 1977: 56: 315-23.

3 Azar H, Nazarian I, Sadrieh M. A study of cause of death in patients with fulminant amebic colitis. $A m J$ Proctol 1977; 28: 80-7.

4 Juniper K. Acute amebic colitis. Am J Med 1962; 33: 377-86.

5 Barrett-Conner E. Chemoprophylaxis of amebiasis and African trypanosomiasis. Ann Intern Med 1972; 77: $797-805$

6 Phillips SC, Mildvan D. William DC et al. Sexual transmission of enteric protozoa and helminths in a venereal-disease-clinic population. N Engl J Med 1981; 305: 603-6.

7 Istre GR, Kreiss K, Hopkins RS et al. An outbreak of amebiasis spread by colonic irrigation at a chiropractic clinic. N Engl J Med 1982; 307: 39-42.

8 Brooke MM. Epidemiology of amebiasis in the United States. JAMA 1964; 188: 519-21.

9 Pittman FE, El-Hashimi WK, Pittman JC. Studies of human amebiasis. II. Light and electron microscopic observations of colonic mucosa and exudate in acute amebic colitis. Gastroenterology 1973; 65: 588-603.

10 Pittman FE, El-Hashimi WK. Pittman JC. Studies of human amebiasis. I. Clinical and laboratory findings in 8 cases of acute amebic colitis. Gastroenterology 1973; 65: $581-7$

11 Elhence IP, Agrawal BM, Sharma BD. Amebic necrosis of bowel. Int Surg 1979; 64: 57-61.

12 Kapur BM, Chopra P. Necrotizing amebic colitis: report of five cases. Dis Colon Rectum 1978; 21 : 447-9.

13 Vajrabukka T, Dhitavat A, Kichananta B et al. Fulminating amoebic colitis: a clinical evaluation. $\mathrm{Br} J$ Surg 1979; 66: 630-2.

14 Cutler D, Avendano E. Maldonado P et al. Necrotic amebic colitis. Am J Gastroenterol 1974; 62: 345-9.

15 Stein D, Bank S, Louw JH. Fulminating amoebic colitis. Surgery 1979; 85: 349-52.

16 Kean BH, Gilmore HR, Van Stone WW. Fatal amebiasis: Report of 148 fatal cases from the Armed Forces Institute of Pathology. Ann Intern Med 1956; 44: 831-43.

17 Grigsby WP. Surgical treatment of amebiasis. Surg Gynecol Obstet 1969; 128: 609-27.

18 Latimer RG. Surgical intervention in intestinal amebiasis. Am J Surg 1975; 41: 385-90.

19 Stein D, Bank S. Surgery in amoebic colitis. Gut 1970; 11: $941-6$.

20 Levin SR. Feldman EA. Acute fulminating amebiasis with multiple complications: report of a survival. Dis Colon Rectum 1968; 11: 359-64.

21 Judy KL. Amebiasis presenting as an acute abdomen. Am J Surg 1974; 127: 275-9. 